\title{
SÓBRE TRIPANOSSOMOS DE ROEDORES SILVESTRES DA REGIÃO DO ARARIPE DO ESTADO DE PERNAMBUCO
}

\author{
Dalva Antunes de Mello e Artur Galileu M. Coelho
}

Vários são os autores que têm pesquisado a presença de tripanossomos em roedôres.

Em 1958 Deane, trabalhando na regiāo do Amazonas, encontrou espécies re roedores silvestres infectados com tripanossomos tipo cruzi, lewisi e outros (4)

Alencar \& col., (1) também encontraram em diferentes regiōes do Ceará, roedores silvestres, peridomésticos e domésticos infectados com Trypanosoma tipo cruzi.

Em São Paulo, Barreto (1964) e Barreto \& cols. (1966) tiveram os mesmos achados dos autores citados, examinando entre outros mamíferos, roedores silvestres e domésticos $(2,3)$.

Todavia, até agora nenhum dado havia sido assinalado no Estado de Pernambuco. Resolveram então, os autores do presente trabalho, aproveitando a coleta sistemática de roedores para estudo ep.demiológico da peste (trabalho que ora se realiza na região da chapada do Araripe dêste Estado), examinar os animais para pesquisa de tripanosomídeos.

\section{MATERIAL E METODOS}

Em vinte e duas localidades p:óximas às cidades de Exu e Bodocó, cento e um roedores, incluindo domésticus, peridomésticas e silvestres, foram capturados, em dias alternados, no periodo de novembro de 1966 a março de 1967.

Os animais foram mantidos em cativeiro durante alguns dias antes de serem examinados.

Inicialmente foi feito exame de sangue a fresco. Daqueles que se mostraram positivos foram feitos estiramentos e gôta espêssa. O sangue foi retirado da cauda dos animais e corado pelo Giemsa.

Medidas, desenhos em câmara clara e fotografia foram feitas daqueles flagelados que se apresentaram com morfologia semelhante a $T$. cruzi.

Do sangue de dois animais que se apresentaram infectados com flageiados tipo cruzi, foram feitas inoculações por via intrapericonial em camuntongos e exame anátomo-patológico dêstes; e, vara outros dois também infectados, foi realizado xenodiagnóstico utilizando-se trinta ninfas de Triatoma infestans e trinta de Rhodnius prolixus.

Para o xenodiagnóstico, os animais foram imobilizados em gaiolas de tela de arame com as seguintes dimensóes: $18 \mathrm{~cm}$ de comprimento $\times 8 \mathrm{~cm}$ de diâmetro e $12 \mathrm{~cm}$ de comprimento $\times 5 \mathrm{~cm}$ de diâmetro, e colocados em seguida no depósito onde se encontravam as ninfas. Estas foram examinadas aos trinta, quarenta e cinqüenta dias após o repasto. 


\section{RESULTADOS}

Animais capturados: Dos animais capturados (Tabela 1) houve uma percentagem de $\mathbf{7 , 9 2 \%}$ de positivos para flagelados do gênero Trypanosoma, sendo que, $3,96 \%$ correspondiam a tipo semelhante a $T$. cruzi e os restantes estavam infe stados por tipo lewisi.

Os animais encontrados infectados com tipo cruzi pertenciam à espécie silvestre Zygodontomys lasiurus pixuna, num total de quatro, e, os animais infectados com $T$. lewisi pertenciam três a Rattus rattus frugivorus e um a $R$. $r$. alexandrinus (Tabela I).

Morfologia das formas encontradas nas lâminas coradas dos animais infectados com tipo semelhante a $T$. cruzi - As formas flagelares que foram observadas nas làminas coradas dos ratos silvestres $(Z$. $l$. pixuna) apresentaram morfolcgia semelhante a $T$. cruzi, isto é, blefaropiasto grande, saliente, próximo a extremidade posterior, membrana ondulante com poucas ondulaçōes (figs. 1 e 2). Entre estas formas caracteristicas, algumas variações foram
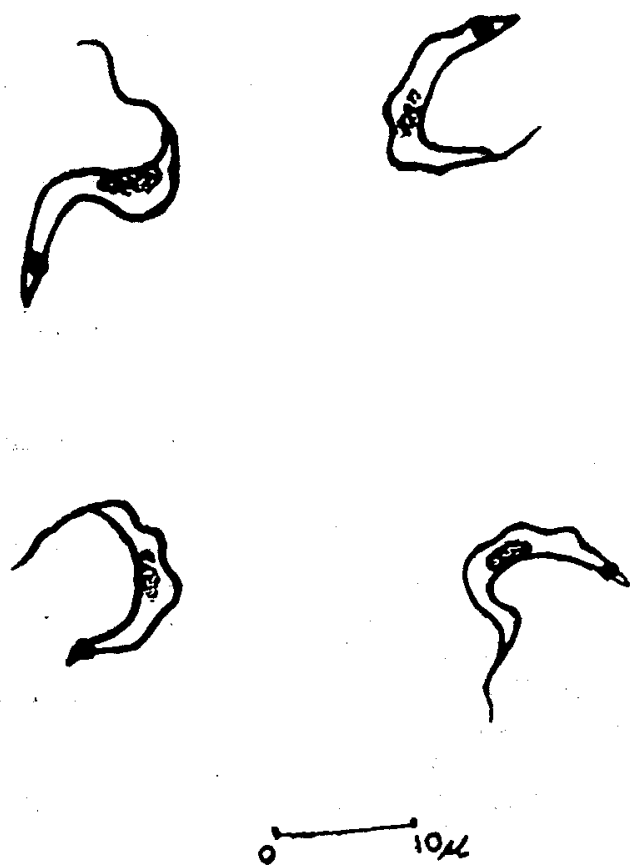

Fig. 1. - Tripanossoma tipo cruzi Desenho em câmara clara. verificadas tais como: algumas mais largas, outras com flagelo mais longos que a habitual, e blefaroplasto muitas vêzes não arredondado em uma forma mais ou menos triangular.

Das medidas realizadas embora com variações, foram encontrados resultados dentro dos que correspondem a $T$. cruzi (Tabela II).

Os camundongos inoculados apresentaram resultados negativos para $T$. cruzi, embora um dêles tenha apresentado discretas lesões miocárdicas compatíveis à doença de Chagas, mas não consideradas como diagnósticas.

Todos os exames do xenodiag:óstico foram negativos.

\section{COMENTÁRIOS E CCNCLUSÓES}

No presente trabalho veriticou-se a presença de tripanossomos do tipo cruzi em Z. l. pixuna e a presença do tipo lewis em $R$. r. frugivorus e $R$. r. alexandrinus.

O fato do resultado ter sido negativo para infecção em camundongos e em triatomíneos não é desconhecido. A variação da virulência do Trypanosoma cruzi para camundongos, assim como também a susceptibilidade de diferentes espécies de triatomíneos à infecção foram assinaladas por Ferriolli \& Barreto $(5,6)$.

Os achados dêste trabalho confirmam a presença de tripanossomos tipo cruzi e lewisi em roedores, à semelhança dos que têm sido assinalado pelos autor.s op. cit. em outros Estados do País.

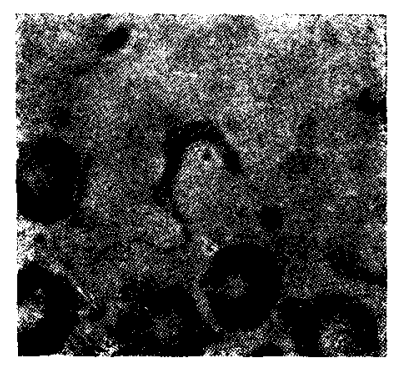

Fig. 2. - Microfotografia (1200 x) de tripanos. soma cruzi em sangue periférico de $Z$ lasiurus pixunc. 
T A B E L A I

ROEDORES EXAMINADOS PARA TRYPANOSOMA EM EXU E BODOCÓ - PERNAMBUCO NOVEMBRO DE 1966 A MARCO DE 1967

\begin{tabular}{|c|c|c|c|c|c|c|c|c|c|c|c|c|c|c|}
\hline \multirow{2}{*}{ ROEDORES } & \multicolumn{2}{|c|}{$\begin{array}{c}\text { Zygodontomys } \\
1 \text { lasiurus } \\
6 \text { pixuna }\end{array}$} & \multicolumn{4}{|c|}{ oryzomis } & \multicolumn{2}{|c|}{$\begin{array}{l}\text { Cercomys } \\
\text { cunicularis } \\
\text { inermis }\end{array}$} & \multicolumn{2}{|c|}{$\begin{array}{l}\text { Calomys } \\
\text { expulsos }\end{array}$} & \multicolumn{2}{|c|}{$\begin{array}{c}\text { Rattus } \\
\text { rattus } \\
\text { rlexandrinus }\end{array}$} & \multicolumn{2}{|c|}{$\begin{array}{c}\text { Rattus } \\
\text { rattus } \\
\text { frugivorus }\end{array}$} \\
\hline & Pos. & Neg. & Pos & Neg. & Pos. & Neg. & Pos. & Neg. & Pos. & Neg. & Pis. & Neg. & Pos. & Neg. \\
\hline Sitio Alagoinha & - & 8 & - & - & 一 & 一 & - & - & - & 2 & - & - & - & - \\
\hline Sítio Alto & - & 1 & $\cdots$ & - & - & - & - & - & - & - & - & 1 & - & - \\
\hline Sítio Beixo & - & 1 & - & - & - & 一 & - & - & - & - & - & - & - & - \\
\hline Sitio Beleza & - & - & - & - & - & - & - & - & - & - & 一 & $\rightarrow$ & - & 1 \\
\hline Sítio Boa Vista & + & - & - & - & - & - & - & 1 & - & - & - & - & -- & - \\
\hline Sítio Brejo & $1(\mathrm{c})$ & $\overline{1}$ & - & - & $-\infty$ & 一 & 一 & - & - & - & - & - & - & - \\
\hline Sitio Bugão & - & 4 & 一 & - & - & 一 & - & - & - & - & - & - & - & - \\
\hline Sítio Cana Mansa & - & 1 & - & 一 & 一 & 一 & - & - & - & 一 & - & - & 一 & 一 \\
\hline Sítio Carmalina & - & - & - & 一 & - & - & - & 1 & - & 一 & 一 & - & - & - \\
\hline Sítio Coroa & - & - & - & - & - & 一 & - & 1 & $\cdots$ & - & - & - & $\cdots$ & - \\
\hline Sitio Gameleira & $\cdots$ & 3 & 一 & - & - & - & 一 & $\overline{0}$ & - & -1 & 一 & - & - & - \\
\hline Sítio Lages & - & 2 & - & 一 & - & 一 & 一 & 2 & - & 1 & - & - & - & - \\
\hline Sítio Mamed" & $\longrightarrow$ & - & - & - & - & - & - & - & - & 一 & - & - & $3(1)$ & - \\
\hline Fazenda Mata Fresca & $-\overline{-}$ & 1 & - & 一 & - & 1 & 一 & - & - & 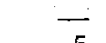 & - & - & -- & 一 \\
\hline Sítio Oriente & $2(\mathrm{c})$ & 22 & $\cdot-$ & - & - & 一 & 一 & - & 一 & 5 & - & - & 一 & - \\
\hline Sítio Paraíso & - & 4 & - & - & - & - & - & - & - & - & - & - & - & - \\
\hline Sitio Pedra Grande & - & 1 & - & 3 & - & - & - & 1 & - & - & - & - & - & - \\
\hline Sitio Recanto & - & 1 & - & 一 & - & - & - & - & - & 一 & - & - & - & - \\
\hline Sítio Retiro & - & 5 & - & - & - & - & - & - & - & 一 & - & - & - & - \\
\hline Sítio Saudaảe & - & 4 & - & 一 & -- & 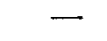 & 一 & - & - & 一 & - & - & - & - \\
\hline Sítio Serra Zé Padeiro & $1(\mathrm{c})$ & - & $\cdots$ & - & - & - & - & - & - & - & - & - & - & - \\
\hline Sítio Toco Prêto & 一 & 4 & 一 & - & - & - & - & - & - & - & $一$ & - & - & 一 \\
\hline Sítio Triunfo & - & $\overline{11}$ & - & - & - & 1 & 一 & 一 & - & - & - & - & - & - \\
\hline Sítio União & - & 11 & - & - & - & - & $-\cdots$ & - & - & - & $\overline{10}$ & - & - & - \\
\hline Fazenda Uruguai & - & - & - & - & 一 & - & - & - & - & - & $1(1)$ & $一$ & -- & - \\
\hline TOTATS & 4 & 73 & - & 3 & - & 2 & 一 & 6 & - & 8 & 1 & 一 & 3 & 1 \\
\hline
\end{tabular}

Pos. $=$ positivo

Neg. = negativo

(c) $=$ tripanossomo tipo cruzi

(1) = tripanossomo tipo levisi 
TABEL I I I

MEDIDAS MÉdIAS, MAXIMAS E MfNIMAS EM $\mu$ DOS TRIPANCSSOMOS TIPO CRUZI ESTUDADOS

\begin{tabular}{|c|c|c|c|}
\hline Medidas Realizadas & Médias & - Máximas & Minimas \\
\hline 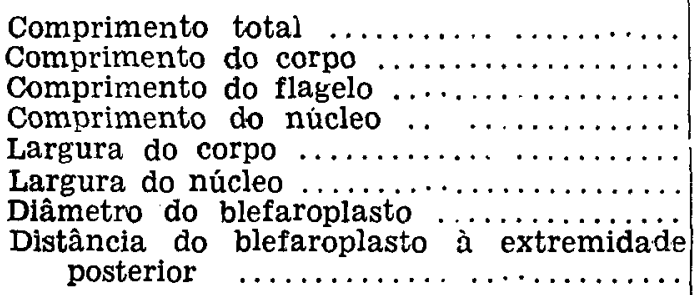 & $\begin{array}{r}29.8 \\
12.5 \\
9.9 \\
3.0 \\
1.9 \\
1.5 \\
1.3 \\
1.5\end{array}$ & $\begin{array}{r}30.0 \\
15.0 \\
10.5 \\
3.0 \\
2.2 \\
1.5 \\
1.3 \\
2.2\end{array}$ & $\begin{array}{r}24.0 \\
10.0 \\
9.0 \\
2.2 \\
1.5 \\
1.5 \\
1.2 \\
1.5\end{array}$ \\
\hline
\end{tabular}

The authors renort the finding of trypanosoma cruzi - like and lewisi in rodents trapped in the Araripe region of the State of Pernambuco, Brazit.

\section{BIBLIOGRAFIA}

1 - ALENCAR, J.E. \& cols. - Estudos sôbre a epiderniologia da Doença de Chagas no Ceará. II. Novos dados. Rev. Brasil. Malarial. e Doen. Trop., 15: 551-565, 1963.

2 - BARRETO, M.P. - Tripanossomos semelhantes ao Trypanosoma cruzi em animais silvestres e sua identificação com o agente etiológico da doença de Chagas. Rev. Inst. Med. Trop. Sẵo Paulo, 7: 505-515, 1965.

3 - BARRETO, M.P. \& cols. - Estudos sôbre reservatórios e vectores silvestres do Trypanosoma cruzi. XI. Observações sôbre um foco natural de tripanossomose americana no Município de Ribeirão Prêto, São Paulo. Rev. Inst. Med. Trop. São Paulo, 8: .... 103-112, 1966.

4 - DEANE, L.M. - Tripanosomideos de mamíferos da Região Amazônica. III
Hemoscopia e xenodiagnóstico de animais silvestres dos arredores de $\mathrm{Be}-$ lém. $\mathbf{R}^{\sim v}$. Inst Med. Trop. São Pau10, 6: 225-232, 1964.

5 - FERRIOLLI FILHO, F. \& BARRETO, M.P. - Estudos sôbre reservatórios e vectores silvestres do Trypanosoma cruzi. VI. Infecção natural do roedor Akodon arviculoides cursor (Weinge 1885) por tripanossomo semelhante ao Trypanosoma cruzi. Rev. Inst. Med. Trop. São Paulo, 7: 72-81, 1965.

6 - FERRICLLI FILHO, F. \& BARRETO, M.P. - Estudos sôbre reservatórios e vectores silvestres do Trypanosoma cruzi. IX. Infecção natural do Rattus rattus (Lin. 1758) por tripanossomo semelhante ao Trypanosoma cruzi. Rev. Inst. Med. Trô. São Paulo, 7: $169-179$, 1965a. 